\title{
Effect of Tutoring on Passing Remedial Mathematics Courses
}

\author{
Yanhong Wua $u^{a}$ Björg Jóhannsdóttira ${ }^{a}$ Viji Sundar ${ }^{a}$ \\ aCalifornia State University Stanislaus, USA
}

The goal of this study was to investigate the effect of tutoring on students passing rate in remedial mathematics algebra courses, and to probe students' own reasons for failing an introductory mathematics course. Two experiments were conducted, one to study the impact of individual tutoring for students taking a remedial course for the second time, and the second to study the impact of an in-class tutoring for a whole group. In both experiments, statistical analysis indicated that tutoring significantly improved passing rate in the remedial courses and increased the mean scores for the first time takers.

KEYWORDS

Remedial Mathematics; Logistic model; Repeated measurement model; Passing rate
ARTICLE HISTORY

Received 10 August 2017

Revised 28 September 2017 Accepted 15 November 2017

\section{Introduction}

Tutoring has been found to be an effective tool for academically underprepared and high-risk students (Hock, et al., 1999, Hodges, 2001). Many forms of tutoring have been studied in the literature. Hendriksen, et al. (2005) studied the effectiveness of several forms of tutoring including such as one-to-one appointment tutoring, walk-ins, group tutoring, peer tutoring, and distance tutoring (by phone, computer etc). Cooper's (2010) results indicated the students who used tutoring center more frequently tended to have higher GPAs. Reinheimer \& McKenzie (2011) conducted a cohort study on undeclared students. Their findings suggested that tutoring positively affects retention rate and degree attainment. A more recent study by Russ (2015) compared the impacts of different tutoring methods on the final grades of at-risk college freshmen. Her findings 
pointed toward self-scheduled, group setting with peer tutor as the most effective form of tutoring. With regards to mathematics courses and the effects of tutoring, the results are mixed. Findings from Xu, et al. (2001) implied that tutoring increased final exam scores; while Navarra-Madsena \& Ingram (2010) found that the number of tutoring hours had no significant effect on final grades.

Our work, different from others, was focused on those students who failed the remedial courses when first attempted. The current pilot study was three-fold: first to study the impact of individual tutoring on the passing rate of students who failed Algebra I (Math 103) and Algebra II (Math 106) first time around, and second, to study how additional targeted tutoring affected learning outcomes, and third, to study what factors students contribute their failure of Calculus I. For the first part of study, treatment (tutoring) was assigned to those students who accepted the offer of individual tutoring; for the second part, the treatment was assigned to one whole session. The target population was all students taking remedial algebra class. For the third part of the study, we questioned those students that had failed or dropped out Calculus I about their reasons for failing/dropping out of the course.

The discussion is organized as follows. In Section 2, we compare the passing rates of those students who failed their remedial course first time, including both Algebra I and II. The results indicated significant increase in passing rate for those students receiving tutoring. Section 3 is devoted to the discussion of increase in mean score by comparing two sections of remedial algebra, in which one section received in-class tutoring and the other one did not. Treating each student as a panel where pre-test and post-test were used as the repeated treatment, we used longitudinal model was used to compare groups. Discussion on the possible reasons for failing is presented in the last section.

\section{Passing Rate for Faıled Students \\ Data Collection}

To gather information on students who had failed remedial mathematics courses, we used data from our university campus for the 2014-2015 academic year. During the fall semester, out of 100 students who took Algebra I (Math 103), 22 failed the class (22\%); while out of 193 who took Algebra II (Math 106), 37 failed (19\%). Of the total of 59 students who failed the remedial classes, 36 retook the class during the spring semester. The remaining 23 students did not retake the course and most of them dropped out of the enrollment.

The current study is concentrated on the 36 students who retook the class. We sent out tutoring invitations to all 36 students, seven of them accepted the invitation. 


\section{Statistical Model}

The tutor and class were treated as the two main factors and fitted a logistic model was fitted for the passing rate (Diggle et al., 2002):

$$
\ln \frac{\mathrm{p}}{1-\mathrm{p}}=80+B 1 \text { (tutor) }+B 2(\text { class })+B 3(\text { tutor }: \text { class })+\text { Error, }
$$

in which tutor $=1,0$ means with/without tutoring, and class $=0,1$ represents Algebra I and II, respectively. The interaction effect is also included. $\mathrm{R}$ is used for all the calculations. Table 1 gives the outcome.

Table 1 Logistic fit under the full model

\begin{tabular}{ccccc}
\hline Source & coefficient & StError & \multicolumn{2}{c}{ z-value $P(>|z|)$} \\
& & & & \\
Intercept & -0.8473 & 0.6901 & -1.228 & 0.220 \\
Tutor & 1.5404 & 1.1073 & 1.391 & 0.164 \\
Class & 0.3083 & 0.8381 & 0.368 & 0.713 \\
Interactio & 15.5646 & 2399.54 & 0.006 & 0.995 \\
\hline
\end{tabular}

From Table 1, we see that the interaction has very little effect. A reduced model looks like

$$
\ln \frac{\mathrm{p}}{1-\mathrm{p}}=B_{0}+B_{1} \text { (tutor) }+B_{2}(\text { class })+\text { Error. }
$$

Table 2 gives the results from the application of reduced model.

Table 2 Logistic Model Fit under the Reduced Model

\begin{tabular}{lcccc} 
Source & coefficient & StError & z-value & $P(>|z|)$ \\
\hline & & & & \\
intercept & -0.9502 & 0.6814 & -1.394 & 0.1632 \\
tutor & 1.8067 & 1.0349 & 1.746 & 0.0808 \\
class & 0.4588 & 0.8072 & 0.568 & 0.5698 \\
\hline
\end{tabular}

From Table 2, we see that the difference between the two classes is not significant and thus only the effect of tutoring is significant, and it becomes a simple comparison of two proportions. Table 3 summarizes the data.

For testing, the passing rate for the tutoring group is significantly higher and the $\mathrm{p}$-value is 0.0375 that shows strong significance and the $90 \%$ confidence interval for the difference is

$0.714-0.345 \pm 1.645(0.714(1-0.714) / 7+0.345(1-0.345) / 29)^{1 / 2}=0.369 \pm 0.316$.

Table 3 Passing Number With/Without Tutoring

\begin{tabular}{ccccc}
\hline tutor\pass & yes & no & total & prop \\
\hline yes & 5 & 2 & 7 & 0.714
\end{tabular}




\begin{tabular}{ccccc} 
no & 10 & 19 & 29 & 0.345 \\
total & 15 & 21 & 36 & 0.42 \\
\hline
\end{tabular}

In summary, the results show significant increase in passing rate for those students receiving tutoring and no significant difference between the two levels of courses

\section{Improvement of Mean Score by Tutoring}

\section{Data Collection and Model}

To study quantitatively the improvement of passing rate by tutoring, we select two sessions of Algebra II (Math 106). The first session had 21 students and a tutor in class during class hours. The second session had 20 students and no in class assistance, except for the instructor. Both sessions had the same instructor. All students from both sessions took a pre-test prior to attending the class and then a post-test at the end of the class. The test scores were out of a total of 40 points. Table 4 summarizes the data.

Table 4 shows that the treatment session had much lower mean pre-test score; while its mean post-test score is much closer to the one for the control session. In both sessions, the improvements of mean scores are evident. The goal of the study was to test whether there was a significant difference in improvements between the two sessions.

Table 4 Test Scores

\begin{tabular}{cccc}
\hline Tutor & size & pre $($ stdev) & post $($ stdev) \\
\hline Yes & 21 & $15.9524(4.70613)$ & $37.1905(5.77598$ \\
No & 20 & 19.8000 & $38.3000(6.08795$ \\
Pooled & 41 & $17.8293(4.91885)$ & $37.7317(5.88228$ \\
\hline
\end{tabular}

\section{Test under Repeated Measurement Model}

We used an ANOVA test under a repeated measurement model by treating the pre- and post-tests as repeated measurements. We used the within-subjects contrasts to test the effect of tutoring. We formulated the full model as

$$
\left.Y_{i j}=B_{0}+B_{1}(\text { tutor })+B_{2} \text { (test) }+B_{3} \text { (tutor }: \text { test }\right)+E_{i j},
$$

In which $i=1, \ldots, 41$ were the index for the subjects and $j=1,2$ represented the pre- and post-tests. To account for the individual effects, it was assumed that $E_{i j}=Z_{i}+W_{i j}$ for $\boldsymbol{i}=1, \ldots, 41$ and $\boldsymbol{j}=1,2$ $\left(Z_{i}\right.$ are independent of $\left.W_{i j}\right)$. The repeated measurement test separated the outcome into between-subjects effect test and within- subject effect test. The between-subject test shows the significance of difference between the marginal means of the two 
groups by ignoring the improvement of test scores. That means that the following model was first tested

$$
Y_{i j}=B_{0}+B_{1} \text { (tutor) }+E_{i j} \text {. }
$$

Table 5 shows the results of the F-test. It shows that the two groups had a significant difference in mean score, indicating a significance difference in the starting condition of the two groups.

Table 5 Test of Between-subjects Effects

\begin{tabular}{cccccc}
\hline Source & Sum of & df & mean & F & sig. \\
\hline Interce & 63384.009 & 1 & 63384.009 & 1545.77 & 0.00 \\
Tutor & 125.863 & 1 & 125.863 & 3.069 & 0.08 \\
Error & 1599.186 & 39 & 41.005 & & \\
\hline
\end{tabular}

The within-subject test further fits the model by adding the effect of test (treated as the control) and more importantly, the interaction effect between test and tutor. This interaction effect demonstrates the significance level of difference of improvement in test scores between the two groups. Table 6 shows the results.

Table 6 Test of Within-subjects Effects

\begin{tabular}{cccccc}
\hline Source & Sum of & df & mean & F & sig. \\
\hline test & 8088.156 & 1 & 8088.156 & 536.09 & .000 \\
test*tut & 38.400 & 1 & 38.400 & 2.545 & 0.11 \\
Error & 588.405 & 39 & 15.087 & & \\
\hline
\end{tabular}

\section{Longitudinal Model Fit}

We used a mixed effect model to take into account the withinsubject correlation by treating each individual as a panel. It predicted that the individual effects would follow a normal random variable with mean zero. We assume the model as

$$
\mathrm{Y}_{\mathrm{ij}}=B_{0}+B_{1} \text { (tutor) }+B_{2}(\text { test })+B_{3}(\text { tutor }: \text { test })+Z_{i}+W_{i j}
$$

In which $Z_{i}$ are i.i.d. random normal variables representing the effect of 41 individuals, $E_{i j}$ are also i.i.d. normal with the same variance. The two sequences are independent.

We first fit a model without interaction. In R (Long, 2012), the command of fitting is

$$
\text { score } \sim(1 \mid \text { id })+\text { tutor }+ \text { test. }
$$

Table 7 gives the fixed effect estimates. The stdev of individual effect estimate was 3.559 and the stdev of the residual was 3.959. Table 7 indicates that marginally, the mean score for post-test was 19.9024 points higher than the pre-test and the mean score for the session 
with tutor was 2.4786 lower than the mean score without tutor; both results are significant.

To take into account the difference of improvement between the two sessions, we added the interaction effect to the model. In $\mathrm{R}$, the command of fitting is score $\sim(1 /$ id $)+$ tutor $*$ test. Table 8 gives the results. To take into account the difference of improvement between the two sessions, we added the interaction effect to the model. In $\mathrm{R}$, the command of fitting is score $\sim(1 /$ id $)+$ tutor $*$ test. Table 8 gives the results.

Table 7 Fixe Effect Estimation without Interaction

\begin{tabular}{cccc}
\hline Parame & estimati & StErr & $\mathrm{t}^{-}$ \\
\hline Intercep & -0.8037 & 1.6568 & -0.485 \\
tutor & -2.4786 & 1.4147 & -1.752 \\
test & 19.9024 & 0.8743 & 22.76 \\
\hline
\end{tabular}

Table 8 Fixe Effect Estimation with Interaction

\begin{tabular}{cccc}
\hline Parame & estimati & StErr & $\mathrm{t}^{-}$ \\
\hline Intercep & 1.300 & 2.102 & 0.618 \\
tutor & -6.586 & 2.938 & -2.242 \\
test & 18.50 & 1.228 & 15.06 \\
tutor:tes & 2.738 & 1.716 & 1.595 \\
\hline
\end{tabular}

The stdev of individual effect estimate was 3.600 and the stdev of the residual was 3.884 . Table 8 shows that the mean improvement from pre-test to post-test was 18.50 and the mean score for the session with tutor was 6.586 lower than the session without tutor. The increase of mean score for the session with tutor was 2.738 higher than the session without tutor with t-value 1.595 , which is significant.

Table 9 Model Comparison

\begin{tabular}{cccccccc} 
& Df AIC & BIC & & log-lik deviance & Chisq & Chi & P-value \\
\hline No inter. & 5 & 504.7 & 516.76 & -247.36 & 494.73 & & \\
Full model & 6 & 504.1 & 518.57 & -246.07 & 492.13 & 2.592 & 0.1074 \\
\hline
\end{tabular}

Table 9 further compares the two models by showing the values of AIC, BIC, log-likelihood, chi-square value, their difference, and the corresponding $\mathrm{p}$-value. The results show that the improvement is significant with one-sided $\mathrm{p}^{-}$value 0.0537 , which is consistent with the results by using the repeated measurement model test.

\section{Discussion for Reasons of Farlure}

Retention of college students has been a major topic since the implementation of Tinto's model (Tinto, 1975, 1993, 2006). Many factors suspected to influence the retention rate have been extensively studied, 
including skill development, family and peer support, role-models, financial support, cultural sensitive campus environment, relationships on campus. Recent studies have focused on the academic support available to students, including tutoring, learning assistance, and supplementary instruction. Results from Cholewa and Ramaswam (2015) indicated that failing a remedial class plays a greater role than GPA or individual counseling, in freshmen's decision to drop out during fall semester. Cholewa and Ramaswam's findings also indicated that individual counseling had positive impact on GPA.

Cherif, et al. (2012) investigated reasons behind failure of courses and college dropout. Their study included 739 college students. Six major reasons for failing and/or dropping out of college identified by those students were motivation (35\%), study habits (17\%), academic preparedness (12\%), external facts (11\%), attitude (11\%), instruction (10\%), and other relevancy issues (4\%). Among the six reasons, motivation and study habits were considered most influential in students' failure or decision to drop out of college. Instruction and other academic supports are distant 6 th.

The first semester of Calculus (Calculus I) is considered to be a gateway course for science majors. A part of our study was to investigate the reasons behind students' failure of Calculus I. We used data from our campus for spring and fall semester 2014. Out of 277 students taking Calculus I, 90 failed or dropped out. Our results identified the main six reasons for failing Calculus I as: lack of time (60\%), lack of support (20\%), lack of effort (13\%), lack of interest (13\%), and instruction (13\%). Supporting Cherif, et al.'s findings, instruction is a major factor in students' failure or drop out.

Based on our results and other research findings, the following actions are recommended to increase passing rate for those students taking remedial mathematics.

1) The college should provide a supportive academic environment by offering tutoring, learning assistance, and possibly supplemental instruction.

2) The college should strive to form a strong learning community by grouping students taking the same remedial courses, in effort to assist then in forming positive relationships and building good study habits.

3) The college should arrange for faculty members or councilors as cultural agents and schedule advising hours for students in need of non-academic support.

The number of students enrolling in college after high school graduation is on the rise. The college has to be ready to assist those students that fail placement tests in mathematics and need remediation. Our findings indicate that tutoring, both in class and one-to-one, by peers, increases passing rate in remedial mathematical 
classes. Thus tutoring should be a feasible option for colleges that wish to provide their students with support during remedial mathematics.

\section{Disclosure statement}

No potential conflict of interest was reported by the authors.

\section{Notes on contributors}

Yanhong Wu - California State University Stanislaus, USA

Björg Jóhannsdóttir - California State University Stanislaus, USA

Viji Sundar - California State University Stanislaus, USA

\section{References}

Cherif, A.H., Adams, G.E., Movahedzadeh, F., Martyn, M.A, \& Dunning, J. (2014). Why do students fail? Faculty perspective. http://cop.hlcommision.org/LearningEnvironments/

Cholewa, B. \& Ramaswam, S. (2015). The effect of counseling on the retention and academic performance of under-prepared freshmen. J. College Student Retention, 17 , 204-225.

Cooper, E. (2010). Tutoring center effectiveness: The effect of drop-in tutoring. Journal of College reading and Learning, 4O(2), 21-34.

Diggle, P.J., Heagerty, P.J., Liang,K-Y., \& Zeger, S.L. (2002). Analysis of Longitudinal Data. 2nd Eds., Oxford University Press.

Hendriksen, S.I., Yang, L., Love, B., \& Hall, M. C. (2005). Assessing academic support: The effects of tutoring on student learning outcomes. Journal of College Reading and Learning, 35(2), 56-65.

Hock, M., Deshler, D., \& Schumaker, J. (1999). Tutoring programs for academically underprepared college students: A review of the literature. Journal of College Reading and Learning, 29(2), 101-122.

Hodges, R. (2001). Encouraging high-risk student participation in tutoring and supplemental instruction. Journal of Developmental Education, 24(3), 2-7.

Long, J.D. (2012). Longitudinal Data Analysis for the Behavioral Sciences Using R. SAGE Publications, Inc.

Lotkowski, V., Robbins, S., \& Noeth, R. (2004). The role of academic and non-academic factors in improving college retention. ACT Policy Report.

Navarra-Madsena, J. \& Ingram, P. (2010). Mathematics tutoring and student success, Procedia Social and Behavioral Sciences, 8, 207-212

Reinheimer, D. \& McKenzie, K. (2011). The impact of tutoring on the academic success of undeclared students. Journal of College Reading and Learning, 41(2), 22-36.

Russ, V.A. (2015). The Relationship between Final Grades and Tutoring of Methods of At-risk College Freshmen. Walden Dissertations and Doctoral Studies.

Tinto, V. (1975). Dropouts from higher education: A theoretical synthesis of recent research. Review of Educational Research, 45, 89-125.

Tinto, V. (1993). Leaving college: Rethinking the causes and cures of student attrition (2nd Ed.). Chicago: University of Chicago Press.

Tinto, V. (2006). Research and practice of student retention: What next? J. College Student Retention, 8, 1-19. 
Xu, Y., Hartman, S., \& Mencke, R. (2001). The effects of peer tutoring on undergraduate students' final examination scores in mathematics. Journal of College Reading and Learning, 32(1), $22-31$. 